\title{
Effect of heat stress during late gestation on immune function and growth performance of calves: Isolation of altered colostral and calf factors
}

\author{
A. P. A. Monteiro, S. Tao, I. M. Thompson, and G. E. DahI ${ }^{1}$ \\ Department of Animal Sciences, University of Florida, Gainesville 32611
}

\begin{abstract}
Calves born to cows exposed to heat stress during the dry period and fed their dams' colostrum have compromised passive and cell-mediated immunity compared with calves born to cows cooled during heat stress. However, it is unknown if this compromised immune response is caused by calf or colostrum intrinsic factors. Two studies were designed to elucidate the effects of colostrum from those innate to the calf. The objective of the first study was to evaluate the effect of maternal heat stress during the dry period on calf-specific factors related to immune response and growth performance. Cows were dried off $46 \mathrm{~d}$ before expected calving and randomly assigned to 1 of 2 treatments: heat stress (HT; $\mathrm{n}=18$ ) or cooling (CL; $\mathrm{n}=18)$. Cows of the CL group were housed with sprinklers, fans and shade, whereas cows of HT group had only shade. After calving, the cows were milked and their colostrum was frozen for the subsequent study. Colostrum from cows exposed to a thermoneutral environment during the dry period was pooled and stored frozen $\left(-20^{\circ} \mathrm{C}\right)$. Within $4 \mathrm{~h}$ of birth, $3.8 \mathrm{~L}$ of the pooled colostrum from thermoneutral cows was fed to calves born to both HT and CL cows. Day of birth was considered study d 0. All calves were exposed to the same management and weaned at d 49. Blood samples were collected before colostrum feeding, $24 \mathrm{~h}$ after birth and twice weekly up to d 28 . Total serum IgG concentrations were determined. Body weight was recorded at birth and at d 15, 30, 45, and 60. Relative to CL calves, HT calves were lighter at birth (38.3 vs. $43.1 \mathrm{~kg}$ ), but no difference in weight gain was observed at d 60. Additionally, HT calves had lower apparent efficiency of $\operatorname{IgG}$ absorption (26.0 vs. $30.2 \%$ ), but no differences were observed for total IgG concentration. The objective of the second study was to evaluate the isolated effect of the colostrum from HT cows on calf immune response and growth performance. The experimental design was identical to the first study, but all calves were born to cows under thermoneutral
\end{abstract}

Received December 31, 2013.

Accepted June 28, 2014.

${ }^{1}$ Corresponding author: gdahl@ufl.edu conditions during the dry period. At birth, calves were blocked by sex and birth weight and then randomly assigned to 1 of 2 treatments, which meant they received pooled colostrum from HT cows or CL cows. No treatment effect was observed on passive immune transfer or on postnatal growth. Thus, heat stress during the last 6 wk of gestation negatively affects the ability of the calf to acquire passive immunity, regardless of colostrum source.

Key words: calf, dry period, heat stress, immunity

\section{INTRODUCTION}

Heat stress (HT) during the dry period affects general cow performance. Tao et al. (2011) reported that it compromises mammary gland development prepartum and decreases milk production in the subsequent lactation (Tao et al., 2011, 2012b). In addition, HT during the dry period impairs cows' immune function (do Amaral et al., 2011) and leads to a greater disease incidence in the postpartum period (Thompson and Dahl, 2012). Heat stress during gestation also has adverse effects on the offspring. Previous studies show that it decreases uterine blood flow (Oakes et al., 1976), placental weight (Alexander and Williams, 1971), and birth weight of the offspring (Collier et al., 1982; Tao et al., 2012a), which suggests compromised fetal growth. Additionally, Tao et al. (2012a) observed decreased total plasma protein concentration and hematocrit, and compromised cellular immune function and passive immune transfer in calves born to cows heat stressed during the dry period relative to calves from cooled dams. However, whether the decreased immune parameters in that study were due to a calf effect or a colostrum effect is unclear because the calves were fed colostrum from their own dam. Data on the effects of HT during the dry period on the colostrum of dairy cows is limited. Nardone et al. (1997) found that high air temperature during late pregnancy decreases the concentration of $\operatorname{IgG}$ and $\operatorname{IgA}$ and the percentage of total protein in the colostrum from the first milking of primiparous dairy cows. Stott et al. (1976) reported that high ambient temperatures impair colostral antibody absorption and increased mortality in the neonatal calf. Additionally, 
Donovan et al. (1986) observed that serum total protein concentration is lower in calves born during summer months in Florida. However, the effect of maternal HT during late gestation on the health and postnatal growth of calves is not well understood. Therefore, the first experiment described herein was designed to evaluate the effect of maternal HT during the dry period on calf-specific factors related to immune response and growth performance. The second study was performed with the objective of evaluating the isolated effect of colostrum from cows under HT during the dry period on calf immune response and postnatal growth.

\section{MATERIALS AND METHODS}

\section{Animals and Experimental Design}

All treatments and procedures of both experiments received approval of the Institutional Animal Care and Use Committee of the University of Florida (Gainesville).

Experiment 1. The experiment took place at the Dairy Unit of the University of Florida (Hague) during the period of July to November 2011. Multiparous Holstein cows were dried off $46 \mathrm{~d}$ before expected calving date and blocked on mature-equivalent milk production of the previous lactation, and then randomly assigned to 1 of 2 treatments: HT or cooling (CL). After dry off, all cows were housed in a freestall barn that provided shade, but the stall areas for CL cows were equipped with sprinklers and fans, whereas those for HT were not. Fans ran continuously, whereas sprinklers turned on automatically for $1.5 \mathrm{~min}$ at 6 -min intervals when ambient temperature exceeded $23.9^{\circ} \mathrm{C}$. After calving, cows from both treatments were housed in the same freestall barn, cooled by shade, sprinklers, and fans as described above (I. M. Thompson, unpublished data). Therefore, the calves born to those cows were heat stressed $(\mathrm{HT} ; \mathrm{n}=18)$ or cooled $(\mathrm{CL} ; \mathrm{n}=18)$ in utero during the final approximately $46 \mathrm{~d}$ of gestation. Three bull calves from each treatment were slaughtered by $7 \mathrm{~d}$ of age for a separate study. Thus, due to an unbalanced sex distribution between treatments, only data from heifer calves (HT: $\mathrm{n}=12$; CL: $\mathrm{n}=14$ ) were used for all analyses related to growth performance, except for birth weight. Within $4 \mathrm{~h}$ after calving, cows were milked and their first colostrum was stored frozen $\left(-20^{\circ} \mathrm{C}\right)$ for experiment 2 (Figure 1). Also, a colostrum sample was collected for future IgG analysis and stored frozen until the assay was performed. Pooled colostrum from cows exposed to thermoneutral conditions during the dry period (i.e., dried off during winter months in Florida) was fed to all calves. Thus, the colostrum composition was identical between treatment groups. Frozen colostrum sourced from another farm was thawed slowly by placing the individual volumes of colostrum in a refrigerator for approximately $48 \mathrm{~h}$. The colostrum was pooled by mixing all of the individual samples together in a large container. Aliquots (3.8-L bottles) of colostrum were then stored frozen $\left(-20^{\circ} \mathrm{C}\right)$ until use. Due to colostrum availability, 2 different pools of colostrum were used during the experiment and were evenly distributed between both treatments. The calving period occurred during the first 2 mo of the experiment. Pooled colostrum 1 was fed to calves born during the first month of the experiment and pooled colostrum 2 during the second month. Calves were fed $3.8 \mathrm{~L}$ of pooled colostrum by esophageal feeder within $4 \mathrm{~h}$ of birth. Day of birth was considered study d 0 . At d 1 , all calves were moved to the calf unit and individually housed in hutches. Water and starter grain (Purina Animal Nutrition LLC and Purina Mills LLC, St. Louis, MO; Table 1) were provided ad libitum. Pasteurized milk was fed twice per day $(0600$ and $1400 \mathrm{~h}$ ). From d 1 to 29, calves were fed $1.9 \mathrm{~L}$ per feeding, increasing to up to $3.8 \mathrm{~L}$ per feeding from d 30 to 41. Pasteurized milk included waste milk from the herd and colostrum with a low score (i.e., $<50 \mathrm{~g} / \mathrm{L}$ measured by a colostrometer). Pasteurization was accomplished by heating the milk to $63^{\circ} \mathrm{C}$ for 45 min. Calves were weaned gradually, starting at d 42 and ending at d 49. From d 42 to 48 , calves were fed $1.9 \mathrm{~L}$ of pasteurized milk in the morning only. At the weaning day, calves had a grain daily intake of at least $0.9 \mathrm{~kg}$. After weaning, calves were kept in the hutches for $10 \mathrm{~d}$ more before being turned out to group pens.

Experiment 2. The experiment took place at the Dairy Unit of the University of Florida during the period of December 2011 to May 2012. The colostrum stored in the first experiment (collected from cows that were heat stressed or cooled during the dry period) was pooled by treatments (the pooled colostrum was produced as described in experiment 1) and fed to calves born to cows that were exposed to a thermoneutral environment during the dry period (i.e., dried off during winter months in Florida). At birth, calves were blocked by sex and birth weight and then randomly assigned to 1 of 2 treatments, which meant they received pooled colostrum from HT cows (HT colostrum; $\mathrm{n}=17$ ) or CL cows (CL colostrum; $\mathrm{n}=16$ ). Calves were fed $3.8 \mathrm{~L}$ of colostrum by esophageal feeder within $4 \mathrm{~h}$ of birth. Day of birth was considered study d 0 . After d 1, all calves were managed as described in experiment 1 .

\section{Growth Measures, Hematocrit, and Total Plasma Protein and Serum IgG Concentrations}

In both studies, calves were weighed at birth before colostrum feeding and then, BW and withers height 
Table 1. Chemical composition (\% of DM, unless otherwise noted) of calf starter ${ }^{1}$

\begin{tabular}{lc}
\hline Chemical composition & Amount \\
\hline CP, minimum & 18.00 \\
Crude fat, minimum & 3.25 \\
Crude fiber, maximum & 8.00 \\
ADF, maximum & 10.00 \\
Ca, minimum-maximum & $0.8-1.2$ \\
P, minimum & 0.64 \\
NaCl, minimum-maximum & $0.4-0.9$ \\
Se, minimum (mg/kg) & 0.33 \\
Vitamin A, minimum (IU/kg) & 13,245 \\
Vitamin $\mathrm{D}_{3}$, minimum (IU $\left./ \mathrm{kg}\right)$ & 5,519 \\
Vitamin E, minimum $(\mathrm{IU} / \mathrm{kg})$ & 26 \\
\hline
\end{tabular}

${ }^{1}$ Purina Animal Nutrition LLC and Purina Mills LLC (St. Louis, MO).

(WH) were measured every $15 \mathrm{~d}$ until d 60. Preweaning BW gain and height increase was calculated by subtracting data at birth or at d 15, respectively, from d-60 values.

Blood samples were collected via jugular venipuncture shortly after birth before colostrum feeding and approximately $24 \mathrm{~h}$ after birth. Additionally, samples were collected twice per week to determine hematocrit and total plasma protein concentrations up to $\mathrm{d}$
35 and 56 and to determine total $\operatorname{IgG}$ concentrations up to d 28 and 7 in experiments 1 and 2, respectively. Sodium-heparinized tubes (Vacutainer; Becton Dickinson, Franklin Lakes, NJ) were used to collect blood to determine hematocrit and total plasma protein concentration. Samples were placed in ice immediately after collection and parameters were assessed within $3 \mathrm{~h}$. To determine total IgG concentration, blood samples were collected using Vacutainer tubes without anticoagulant and placed at room temperature $\left(27^{\circ} \mathrm{C}\right)$ until clotted, and then serum was separated through centrifugation at $3,000 \times g$ for $30 \mathrm{~min}$ at $4^{\circ} \mathrm{C}$, aliquoted, and stored frozen $\left(-20^{\circ} \mathrm{C}\right)$ until time of assay.

\section{Health Scoring}

Health scores were recorded 3 times per week $(0800$ $\mathrm{h})$ in experiment 1 and daily $(0800 \mathrm{~h})$ in experiment 2. Temperatures were measured only during the first $28 \mathrm{~d}$ of age for a subset of heifer calves (HT: $\mathrm{n}=5$; CL: $\mathrm{n}=7$ ) in experiment 1 and for all calves during the entire preweaning period in experiment 2. Health events were evaluated based on a health scoring chart (Table 2) adapted from School of Veterinary Medicine,

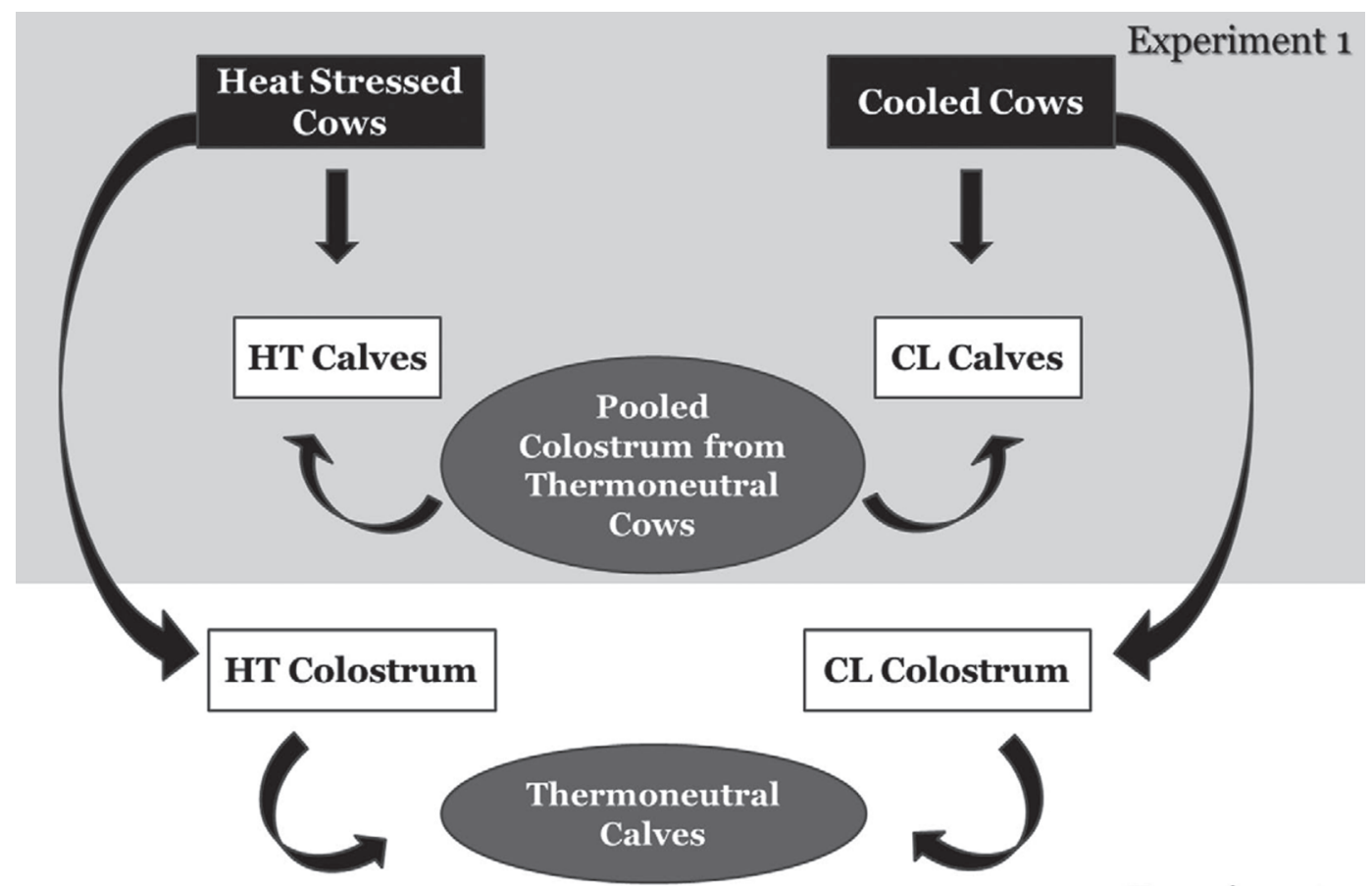

Experiment 2

Figure 1. Schematic description of experiments 1 and 2. In experiment 1, calves born to heat-stressed (HT) or cooled (CL) cows during the dry period were fed a pooled colostrum previously collected from cows exposed to thermoneutral conditions during late gestation. Thus, the colostrum composition was identical between treatment groups. In experiment 2, the first colostrum stored frozen from the first experiment was pooled and fed to calves born to cows that were under a thermoneutral environment during the dry period. Therefore, calves were fed pooled colostrum from cows that were heat stressed (HT colostrum) or cooled (CL colostrum) during the final approximately $46 \mathrm{~d}$ of gestation. 
Table 2. Calf health scoring criteria ${ }^{1}$

\begin{tabular}{|c|c|c|c|c|}
\hline Clinical sign & \multicolumn{4}{|c|}{ Score } \\
\hline Cough & None & Induce single cough & $\begin{array}{l}\text { Induced repeated coughs or } \\
\text { occasional spontaneous cough }\end{array}$ & $\begin{array}{l}\text { Repeated spontaneous } \\
\text { coughs }\end{array}$ \\
\hline Nasal discharge & $\begin{array}{l}\text { Normal serous } \\
\text { discharge }\end{array}$ & $\begin{array}{l}\text { Small amount of unilateral } \\
\text { cloudy discharge }\end{array}$ & $\begin{array}{l}\text { Bilateral, cloudy, or excessive } \\
\text { mucus discharge }\end{array}$ & $\begin{array}{l}\text { Copious bilateral } \\
\text { mucopurulent discharge }\end{array}$ \\
\hline Eye scores & Normal & $\begin{array}{l}\text { Small amount of ocular } \\
\text { discharge }\end{array}$ & $\begin{array}{l}\text { Moderate amount of bilateral } \\
\text { discharge }\end{array}$ & Heavy ocular discharge \\
\hline Fecal scores & Normal & Semi-formed, pasty & $\begin{array}{l}\text { Loose, but stays on top of } \\
\text { bedding }\end{array}$ & $\begin{array}{l}\text { Watery, sifts through } \\
\text { bedding }\end{array}$ \\
\hline Rectal temperature $\left({ }^{\circ} \mathrm{C}\right)$ & $37.8-38.3$ & $38.4-38.8$ & $38.9-39.4$ & $\geq 39.5$ \\
\hline
\end{tabular}

${ }^{1}$ Adapted from School of Veterinary Medicine, University of Wisconsin-Madison (2011).

University of Wisconsin-Madison (2011). Respiratory score was calculated, combining observed scores for cough, nasal discharge, rectal temperature, and the highest score between ear and eye discharge. Calves were diagnosed with diarrhea when they had a fecal score of at least 2 .

\section{Ovalbumin Challenge}

In both studies, an ovalbumin solution containing albumin from chicken egg white $(0.5 \mathrm{mg} / \mathrm{mL}$; SigmaAldrich, St. Louis, MO) and adjuvant Quil A (0.5 mg/ mL; Accurate Chemical \& Scientific Corp., Westbury, $\mathrm{NY}$ ) was prepared and $1 \mathrm{~mL}$ of the solution was injected s.c. at d 28 and 42 in experiment 1 and at d 7, 28, and 42 in experiment 2. To determine concentrations of IgG produced against ovalbumin, blood samples for serum were collected at d 28, 35, 42, 49, and 56 in experiment 1 and at $d 7,18,28,32,35,39,42,45,49$, and 56 in experiment 2. Serum was aliquoted and stored frozen $\left(-20^{\circ} \mathrm{C}\right)$ until the assay was performed.

\section{IgG Analyses}

For both studies, the total IgG concentration of colostrum and serum samples was measured by the single radial immunodiffusion test (SRID; Triple J Farms, Bellingham, WA) according to the manufacturer's protocol. Briefly, the wells in the plates containing antibovine IgG antibody in agarose gel were filled with 5 $\mu \mathrm{L}$ of diluted colostrum or serum sample and incubated for $27 \mathrm{~h}$ at room temperature in the absence of light. After the end of incubation, the diameter of the precipitin ring was measured and the total IgG concentration was calculated based on the linear relationship between ring diameter squared and total $\operatorname{IgG}$ concentration. The interassay coefficient of variation for serum and colostrum samples was 5.6 and $3.6 \%$ in experiment 1 , and 1.9 and $2.7 \%$ in experiment 2 , respectively. To calculate the apparent efficiency of absorption (AEA), a formula described by Quigley and Drewry (1998) was used. The concentration $(\mathrm{g} / \mathrm{L})$ of total serum IgG at $24 \mathrm{~h}$ after birth was multiplied by the birth weight $(\mathrm{kg})$ and by 0.091 , assuming that the serum volume is consistently $9.1 \%$ of the birth weight, as reported in Quigley et al. (1998). The value obtained was divided by the amount of $\operatorname{IgG}(\mathrm{g})$ fed to the calf and then multiplied by 100 , giving the percentage of absorption of $\mathrm{IgG}$.

The concentration of IgG anti-ovalbumin was measured by ELISA as described by Mallard et al. (1997). Briefly, flat-bottom, 96-well high-binding-affinity plates (Immulon 2 HB; Fisher, Pittsburgh, PA) were coated with sodium carbonate-bicarbonate buffer ( $\mathrm{pH}$ 9.6) containing $1.4 \mathrm{mg}$ of ovalbumin $/ \mathrm{mL}$ and incubated at $4^{\circ} \mathrm{C}$ for $48 \mathrm{~h}$. Following incubation, plates were washed 4 times in a plate washer (ELX50; BioTek instruments Inc., Winooski, VT) with wash buffer solution ( $\mathrm{pH}$ 7.4) containing PBS and $0.05 \%$ Tween-20 detergent solution (Fisher). A blocking solution, containing PBS (pH 7.4), 3\% Tween-20, and 1\% BSA (Sigma-Aldrich), was then added and plate incubated for $1 \mathrm{~h}$ at room temperature. Plates were washed 4 times and $100 \mu \mathrm{L}$ of diluted control serum and sera samples (1:50 in washing buffer solution) was added to the plate and incubated at room temperature for $2 \mathrm{~h}$. Positive and negative controls were run in quadruplicate, whereas test samples were run in duplicates that were placed in separate diagonal-plate quadrants. Next, plates were washed 4 times and $100 \mu \mathrm{L}$ of alkaline phosphatase conjugated rabbit anti-bovine IgG (Sigma-Aldrich), diluted in Tris buffer [Tris-buffered saline (pH 7.4), with $0.05 \%$ Tween] to a ratio of 1:38,000, was added to each well, and then plates were incubated for $1 \mathrm{~h}$ at room temperature. After an additional 4 washes, $80 \mu \mathrm{L}$ of $p$ nitrophenyl phosphate liquid substrate (Sigma-Aldrich) was added to each well and plates were incubated for 30 min at room temperature in the absence of light. At the end of the incubation, plates were read immediately on 
an ELISA plate reader (MRX Revelation; Dynex Technologies Inc., Chantilly, VA) set at an absorbance of 450 and $600 \mathrm{~nm}$ background wavelength. The number of animals from each treatment was balanced in each plate. The inter- and intraassay coefficients of variation were 3.5 and $8.9 \%$, respectively. The data are reported as the optical density of each sample divided by the optical density of the positive control from the respective plate.

\section{Whole-Blood Cell Proliferation}

Blood samples $(20 \mathrm{~mL})$ were collected into sodiumheparinized tubes (Vacutainer; Becton Dickinson) at d $7,28,42$, and $56( \pm 3 \mathrm{~d})$ in experiment 1 and at $\mathrm{d} 7,14$, 28,42 , and $56( \pm 3 \mathrm{~d})$ in experiment 2 and immediately transported to the laboratory at ambient temperature. Additionally, another blood sample $(7 \mathrm{~mL})$ was collected into tubes containing EDTA and immediately transported under ambient temperature to be analyzed for white blood cell (WBC) count at the laboratory located in the Veterinary Medical Teaching Hospital at the University of Florida. Briefly, modified RPMI medium (medium RPMI 1640 \#11835 supplemented with $1 \%$ antibiotic-antimycotic, 100×; Gibco; Life Technologies, Grand Island, NY) was used to dilute blood samples. Diluted whole blood $(100 \mu \mathrm{L} /$ well, 1:15 in modified RPMI) was plated in triplicate and stimulated or not with $5 \mu \mathrm{g} / \mathrm{mL}$ of concanavalin A (SigmaAldrich) in a 96-well, flat-bottom sterile plate. Diluted blood was plated with $10 \mu \mathrm{L}$ of diluted concanavalin A $(100 \mu \mathrm{g} / \mathrm{mL}$ in modified RPMI) or PBS (for control) and $90 \mu \mathrm{L}$ of modified RPMI medium to reach a final volume of $200 \mu \mathrm{L}$. The plate was incubated at $37^{\circ} \mathrm{C}$ and $5 \% \mathrm{CO}_{2}$ for $72 \mathrm{~h}$. After $48 \mathrm{~h}$ of incubation, $10 \mu \mathrm{L}$ of ${ }^{3}[\mathrm{H}]$-thymidine $(3,700 \mathrm{~Bq} / \mu \mathrm{L}$; MP Biomedicals LLC, Santa Ana, CA) was added to each well. At the end of the incubation, cells were harvested onto fiberglass filters using a cell harvester (Brandel Inc., Gaithersburg, $\mathrm{MD}$ ) and then read using a liquid scintillation counter (LS6000; Beckman Coulter Inc., Fullerton, CA). Results were analyzed based on the number of lymphocytes and monocytes present in the culture. Data are reported as net counts per minute (counts per minute of control wells subtracted from stimulated wells) for each 100 cells (i.e., lymphocytes and monocytes only).

\section{Cortisol Analysis}

In experiment 1 , serum samples collected at birth and $1,4,7,14,21,28,35,42,49$, and $56 \mathrm{~d}$ of age were analyzed for circulating cortisol. To determine cortisol concentrations, an RIA was performed using a commercial kit (Coat-A-Coat Cortisol Kit; Siemens Healthcare Diagnostics, Deerfield, IL). The inter- and intraassay coefficients of variation were 5.1 and $10.4 \%$, respectively.

\section{Statistical Analyses}

Colostrum production, colostrum IgG concentration, birth weight, weight at d 60, BW gain, ADG, and AEA were analyzed by ANOVA using PROC GLM of SAS (version 9.2; SAS Institute Inc., Cary, NC) and least squares means \pm standard error of the mean are reported. The ADG was calculated using PROC REG of SAS (version 9.2). Repeated measures (BW and $\mathrm{WH}$ from d 15 to 60; temperature; hematocrit; total plasma protein, IgG, and cortisol concentrations; and whole-blood cell proliferation) were analyzed by ANOVA using PROC MIXED of SAS (version 9.2) and least squares means \pm standard error of the mean are presented; in cases where the number of observations for each treatment differed, the greater standard error of the mean is reported. In both experiments, the SAS models included fixed effects of treatment, time, and treatment by time interaction, with calf or cow within the treatment as a random effect. In experiment 1, the SAS models for hematocrit, total plasma protein and serum IgG concentrations, and AEA included fixed effects of pooled colostrum and treatment by colostrum interaction. In experiment $2, \mathrm{BW}$ and $\mathrm{WH}$ at birth were included in the SAS model as covariates for statistical analysis of BW and $\mathrm{WH}$ at weaning, respectively. To analyze the incidence of health scores, a chi-squared test was performed using PROC FREQ of SAS (version 9.2). Differences with $P \leq 0.05$ were considered statistically significant.

\section{RESULTS}

\section{Cow Performance}

The stall areas for both CL and HT dams had a similar temperature-humidity index $(78.2 \pm 0.16$ vs. 77.9 \pm 0.16 , respectively), which indicates that both groups of cows were exposed to a similar thermal environment during the dry period, such that in the absence of active cooling, heat stress was readily apparent (I. M. Thompson, unpublished data). Dams from the HT treatment had greater rectal temperature both in the morning $(P$ $=0.01)$ and in the afternoon $(P<0.01)$ and greater respiration rate $(P<0.01)$ compared with those in the cooling system (Table 3). Additionally, HT dams had shorter gestation length $(P=0.03)$ and, consequently, shorter dry period length $(P=0.05)$ compared with CL dams (Table 3). Moreover, cows exposed to cooling 
Table 3. Dry period length, gestation length, rectal temperatures, respiration rate, colostrum production and IgG concentration in colostrum from dams exposed to either heat stress $(n=18)$ or cooling $(n=18)$ during the dry period

\begin{tabular}{lrrrr}
\hline Variable & $\begin{array}{c}\text { Heat } \\
\text { stress }\end{array}$ & Cooling & SEM & $P$-value \\
\hline Dry period length $(\mathrm{d})$ & 35.4 & 39.1 & 1.30 & 0.05 \\
Gestation length $(\mathrm{d})$ & 27.5 & 275.4 & 1.26 & 0.03 \\
Rectal temperature, a.m. $\left({ }^{\circ} \mathrm{C}\right)$ & 38.6 & 38.5 & 0.04 & 0.01 \\
Rectal temperature, p.m. $\left({ }^{\circ} \mathrm{C}\right)$ & 39.4 & 38.9 & 0.06 & $<0.01$ \\
Respiration rate $($ breaths $/ \mathrm{min})$ & 79.2 & 44.6 & 2.42 & $<0.01$ \\
Colostrum yield $^{1}(\mathrm{~L})$ & 7.2 & 6.4 & 1.07 & 0.52 \\
Colostrum IgG $^{1}(\mathrm{~g} / \mathrm{L})$ & 86.8 & 94.7 & 7.66 & 0.46 \\
Total IgG produced $^{1}(\mathrm{~g})$ & 627.8 & 549.2 & 91.60 & 0.54 \\
${\text { Colostrum IgG }<50 \mathrm{~g} / \mathrm{L}^{1}(\%)}$ & 16.67 & 6.25 & - & 0.60 \\
\hline
\end{tabular}

${ }^{1}$ Referent to the colostrum produced at the first milking.

during the dry period tended to produce more milk $(33.8 \pm 1.5$ vs. $30.0 \pm 1.5 \mathrm{~kg} / \mathrm{d} ; P=0.1)$ until $40 \mathrm{wk}$ postpartum, compared with HT cows (I. M. Thompson, unpublished data).

\section{Colostrum IgG Concentration}

In experiment 1 , the $\operatorname{IgG}$ concentrations in the pools of thermoneutral colostrum 1 and 2 were 108.8 and $109.9 \mathrm{~g} / \mathrm{L}$ (Table 4), providing 411.1 and $413.3 \mathrm{~g}$ of $\operatorname{IgG}$ for the calves, respectively. No differences were observed in the amount of colostrum produced $(P=$ $0.52)$, mean $\operatorname{IgG}$ concentration in colostrum $(P=0.46)$, or total IgG produced $(P=0.54)$ by cows from each treatment group at the first milking (Table 3 ).

In experiment 2 , the pooled colostrum from $\mathrm{HT}$ or CL cows had an IgG concentration of 109.4 and 96.3 $\mathrm{g} / \mathrm{L}$ (Table 5), providing to the calves 413.7 and 364.1 $\mathrm{g}$ of IgG, respectively. The average time between calving and colostrum feeding for CL and HT treatments was 2.4 and $2.6 \mathrm{~h}$ in experiment 1 and 2.8 and $2.7 \mathrm{~h}$ in experiment 2 , respectively.

\section{Growth Performance}

Calves heat stressed in utero weighed less $(P<0.01)$ at birth and at d 60 than CL calves (Table 6). Additionally, calves cooled in utero were taller $(P<0.01)$ and heavier $(P<0.01)$ during the preweaning period than the calves under HT in utero (Figure 2), but no differences in weight gain, ADG, and height increase were observed at d 60 (Table 6).

In experiment 2, calves in both treatments had similar birth weight, as expected (Table 5). Additionally, calves that received colostrum from HT cows did not differ in growth performance compared with calves that received colostrum from CL cows, so both treatment groups had similar BW gain, ADG, and height increase during the preweaning period and were weaned at similar BW and WH (Table 5).

\section{Health Scores and WBC Count}

In experiment 1, no differences were observed between treatments for fecal and respiratory score dur-

Table 4. Hematocrit, total plasma protein and serum IgG concentrations, and apparent efficiency of absorption (AEA) of calves born to cows exposed to either heat stress $(\mathrm{HT} ; \mathrm{n}=18)$ or cooling $(\mathrm{CL} ; \mathrm{n}=18)$ during the dry period and fed a pooled colostrum $(\mathrm{PC} 1 \text { or PC } 2)^{1}$

\begin{tabular}{|c|c|c|c|c|c|c|c|c|}
\hline \multirow[b]{2}{*}{ Variable } & \multicolumn{2}{|c|}{ PC 1} & \multicolumn{2}{|c|}{$\mathrm{PC} 2$} & \multirow[b]{2}{*}{ SEM } & \multicolumn{3}{|c|}{$P$-value } \\
\hline & $\mathrm{HT}$ & CL & HT & $\mathrm{CL}$ & & $\mathrm{Trt}^{2}$ & Colostrum & $\begin{array}{c}\text { Colostrum } \\
\times \text { Trt }\end{array}$ \\
\hline Hematocrit $^{3}(\%)$ & 29.7 & 27.2 & 23.8 & 25.7 & 1.3 & 0.89 & 0.04 & 0.21 \\
\hline Total plasma protein ${ }^{3}(\mathrm{~g} / \mathrm{dL})$ & 5.46 & 5.45 & 5.37 & 5.51 & 0.07 & 0.42 & 0.82 & 0.36 \\
\hline Serum $\operatorname{IgG}^{4}(\mathrm{~g} / \mathrm{L})$ & 23.4 & 22.4 & 18.6 & 20.6 & 0.9 & 0.69 & 0.02 & 0.26 \\
\hline
\end{tabular}

${ }^{1}$ Due to colostrum availability, 2 pooled colostrums were used throughout the experiment.

${ }^{2} \mathrm{Trt}=$ treatment.

${ }^{3}$ Blood samples were taken twice per week up to d 35 of age.

${ }^{4}$ Blood samples were taken at $\mathrm{d} 1,7,14,21$, and 28 of age.

${ }^{5} \mathrm{AEA}=[\operatorname{serum} \operatorname{IgG}(\mathrm{g} / \mathrm{L}) \times$ birth weight $(\mathrm{kg}) \times 0.091 / \operatorname{IgG}$ fed $(\mathrm{g})] \times 100$. 
Table 5. Hematocrit, total plasma protein and serum IgG concentrations, apparent efficiency of absorption (AEA), birth weight, and growth performance of calves born to cows under thermoneutral conditions during the dry period and fed frozen pooled colostrum from cows exposed to either heat stress (HT colostrum; $\mathrm{n}=$ 17) or cooling (CL colostrum; $\mathrm{n}=16$ ) during the dry period

\begin{tabular}{|c|c|c|c|c|}
\hline Variable & HT colostrum & CL colostrum & SEM & $P$-value \\
\hline Colostrum IgG (g/L) & 109.4 & 96.3 & - & - \\
\hline Hematocrit $^{1}(\%)$ & 26.5 & 27.7 & 1.3 & 0.46 \\
\hline Total plasma protein ${ }^{1}(\mathrm{~g} / \mathrm{dL})$ & 5.82 & 5.79 & 0.08 & 0.68 \\
\hline Total serum $\operatorname{IgG}^{2}(\mathrm{~g} / \mathrm{L})$ & 26.9 & 24.0 & 1.4 & 0.08 \\
\hline Total serum IgG at $24 \mathrm{~h}$ of age $(\mathrm{g} / \mathrm{L})$ & 32.4 & 28.6 & 1.8 & 0.05 \\
\hline $\operatorname{AEA}^{3}(\%)$ & 27.5 & 27.6 & 1.8 & 0.95 \\
\hline Birth weight $(\mathrm{kg})$ & 38.8 & 39.2 & 1.5 & 0.80 \\
\hline Weaning weight ${ }^{4}(\mathrm{~kg})$ & 65.9 & 62.0 & 2.4 & 0.12 \\
\hline Weaning withers height ${ }^{4}(\mathrm{~cm})$ & 83.6 & 83.0 & 0.6 & 0.30 \\
\hline Preweaning BW gain $^{5}(\mathrm{~kg})$ & 27.5 & 23.8 & 2.4 & 0.14 \\
\hline $\mathrm{ADG}(\mathrm{kg} / \mathrm{d})$ & 0.47 & 0.40 & 0.04 & 0.12 \\
\hline Preweaning height increase $(\mathrm{cm})$ & 7.4 & 6.8 & 0.6 & 0.27 \\
\hline \multicolumn{5}{|c|}{ Blood samples were taken twice per week up to d 56 of age. } \\
\hline \multicolumn{5}{|c|}{${ }^{2}$ Blood samples were taken at $\mathrm{d} 1,4$, and 7 of age. } \\
\hline \multicolumn{5}{|c|}{${ }^{3} \mathrm{AEA}=[\operatorname{serum} \operatorname{IgG}(\mathrm{g} / \mathrm{L}) \times$ birth weight $(\mathrm{kg}) \times 0.091 / \operatorname{IgG}$ fed $(\mathrm{g})] \times 100$} \\
\hline \multicolumn{5}{|c|}{${ }^{4}$ Weaning weight and weaning withers height were measured at d 60 of age. } \\
\hline
\end{tabular}

ing the preweaning period (Table 7). Additionally, no significant difference was detected for incidence of high respiratory score (score 4 or greater was considered high) for calves born to HT cows compared with those born to CL cows (Table 7). When analyzing only temperature, calves born to HT cows had similar rectal temperature during the first $35 \mathrm{~d}$ of life compared with CL calves (Table 7). Regarding WBC count, no effect of treatment was observed for number and percentage of lymphocytes, monocytes, and neutrophils (Table 8). However, a treatment by day interaction was detected, such that CL calves tended to have fewer neutrophils at d $42(P=0.07)$ compared with HT calves (Table 8). Additionally, a treatment by time interaction was detected, such that CL calves had a lower percentage of neutrophils $(P=0.04)$ and a greater percentage of lymphocytes $(P<0.05)$ at d 42 compared with HT calves (Table 8 ).
In experiment 2 , the fecal and respiratory scores during the preweaning period were similar between treatments (Table 9). However, calves fed colostrum from HT cows had greater rectal temperature $(P<0.01)$ compared with those fed CL colostrum (Table 9).

\section{Hematocrit and Total Plasma Protein and Serum IgG Concentrations}

In both experiments, no case of failure of passive immune transfer (i.e., total serum IgG concentration lower than $10 \mathrm{~g} / \mathrm{L}$ ) was detected. In experiment 1, treatments did not affect the hematocrit $(P=0.89)$ or total plasma protein concentration $(P=0.42)$ of calves from birth to d 35 (Table 4). Heat stress during the dry period also did not affect the total serum IgG concentration of the offspring at $24 \mathrm{~h}$ after birth $(P=0.59)$ or during the first $28 \mathrm{~d}$ of life $(P=0.69)$ compared with CL (Table

Table 6. Birth weight and growth performance of heifer calves born to cows exposed to either heat stress (HT calves; $\mathrm{n}=12$ ) or cooling (CL calves; $\mathrm{n}=14$ ) during the dry period and fed pooled colostrum

\begin{tabular}{|c|c|c|c|c|}
\hline Variable & HT calves & CL calves & SEM & $P$-value \\
\hline Birth weight $^{1}(\mathrm{~kg})$ & 38.3 & 43.1 & 1.2 & $<0.01$ \\
\hline Weaning weight ${ }^{2}(\mathrm{~kg})$ & 67.0 & 76.0 & 2.5 & $<0.01$ \\
\hline Weaning withers height ${ }^{2}(\mathrm{~cm})$ & 83.1 & 85.7 & 0.7 & $<0.01$ \\
\hline Preweaning BW gain $^{3}(\mathrm{~kg})$ & 30.4 & 34.2 & 2.0 & 0.17 \\
\hline $\mathrm{ADG}(\mathrm{kg} / \mathrm{d})$ & 0.52 & 0.57 & 0.03 & 0.27 \\
\hline Preweaning height increase $^{3}(\mathrm{~cm})$ & 5.7 & 6.0 & 0.9 & 0.84 \\
\hline
\end{tabular}

${ }^{1}$ Included data from male and female calves $(\mathrm{HT}=18 ; \mathrm{CL}=18)$.

${ }^{2}$ Weaning weight and weaning withers height were measured at $\mathrm{d} 60$ of age.

${ }^{3}$ Preweaning BW gain and height increase were calculated by individually subtracting data at d 60 of age by data at birth or at $\mathrm{d} 15$ of age, respectively. 
Table 7. Health scores during the first $60 \mathrm{~d}$ of age of calves born to cows heat stressed (HT calves; $\mathrm{n}=18$ ) or cooled (CL calves; $\mathrm{n}=18$ ) during the dry period

\begin{tabular}{|c|c|c|c|c|c|c|}
\hline \multirow[b]{2}{*}{ Variable } & \multicolumn{2}{|c|}{ Treatment } & \multirow[b]{2}{*}{ SEM } & \multicolumn{3}{|c|}{$P$-value } \\
\hline & HT calves & CL calves & & Treatment & Time & $\begin{array}{l}\text { Treatment } \\
\quad \times \text { time }\end{array}$ \\
\hline Fecal score $(0-3)$ & 1.50 & 1.61 & 0.08 & 0.27 & $<0.01$ & 0.88 \\
\hline Respiratory score $(0-12)$ & 2.19 & 2.18 & 0.12 & 0.91 & 0.03 & 0.85 \\
\hline Respiratory score $\geq 4(\%)$ & 43.75 & 12.50 & - & 0.11 & - & - \\
\hline Rectal temperature ${ }^{1}\left({ }^{\circ} \mathrm{C}\right)$ & 39.10 & 38.93 & 0.07 & 0.10 & $<0.01$ & 0.51 \\
\hline
\end{tabular}

${ }^{1}$ Temperature was measured for a subset of animals ( $\left.\mathrm{HT}=5 ; \mathrm{CL}=7\right)$ and only during the first $35 \mathrm{~d}$ of age.

4). Despite the lack of difference in the total serum IgG concentration at $24 \mathrm{~h}$ after birth, calves exposed to HT in utero had lower AEA compared with calves cooled in utero $(26.0 \pm 1.4$ vs. $30.2 \pm 1.4 \% ; P=0.05$; Table 4). An effect of the pooled colostrum was detected, as calves that received pooled colostrum 1 had greater hematocrit $(P=0.04)$, serum IgG concentration at $24 \mathrm{~h}$
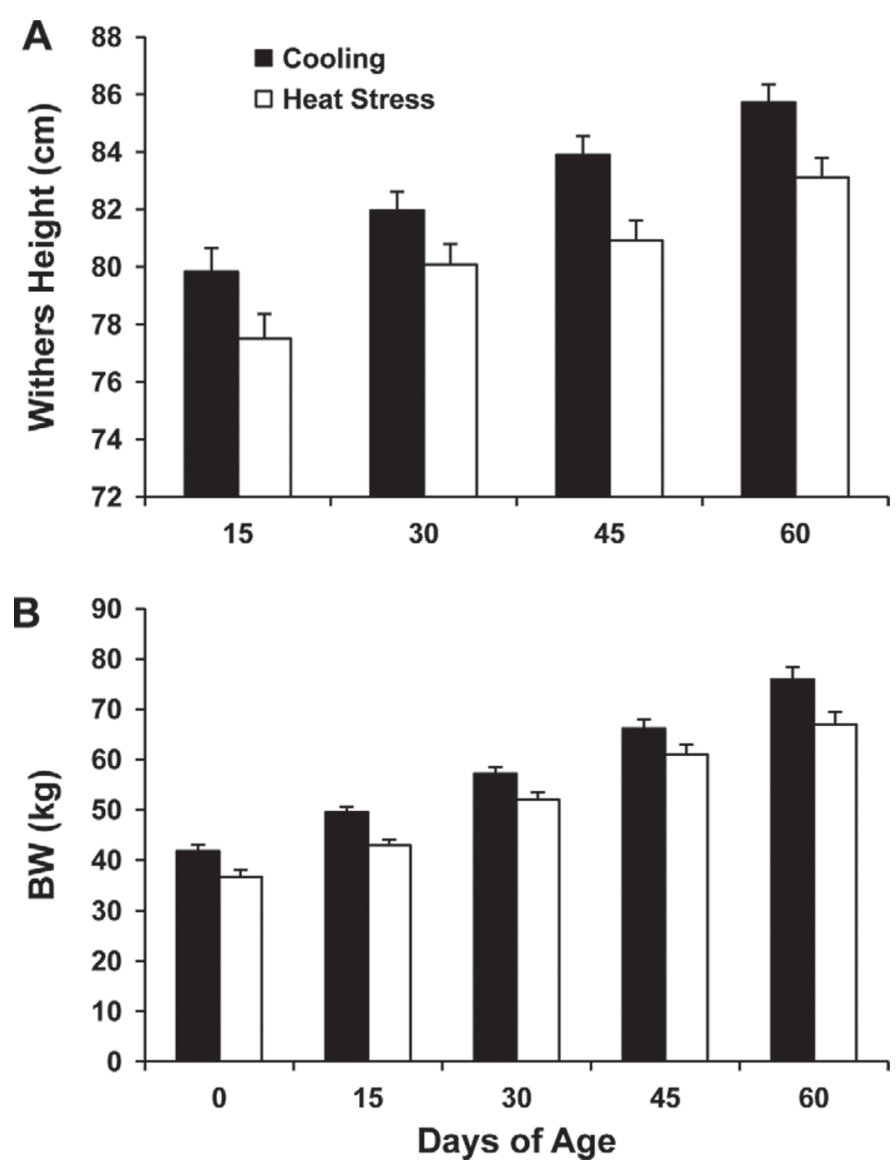

Figure 2. Effect of heat stress or cooling during the dry period on preweaning growth performance of the offspring. Error bars represent SEM. Calves born to cows exposed to cooling were taller (panel A; $82.9 \pm 0.5$ vs. $80.4 \pm 0.6 \mathrm{~cm} ; P<0.01$ ) and heavier (panel B; $58.1 \pm$ 1.3 vs. $51.9 \pm 1.4 \mathrm{~kg} ; P<0.01)$ compared with those born to heatstressed cows. after birth $(P<0.01)$, serum IgG concentration during the first $28 \mathrm{~d}$ of life $(P=0.02)$, and also greater AEA $(P<0.01)$ than those that received pooled colostrum 2 (Table 4). However, no interaction was detected between treatment and pooled colostrum (Table 4).

In experiment 2 , treatments did not affect the hematocrit $(P=0.46)$ and total plasma protein concentration $(P=0.68)$ from birth to d 56 (Table 5$)$. Total serum IgG concentration at $24 \mathrm{~h}$ was lower $(P=0.05)$ in the calves that received colostrum from CL cows compared with those that received colostrum from HT cows, but no treatment effect was observed for AEA ( $P$ $=0.95 ;$ Table 5 ).

\section{Ovalbumin Challenge Response}

In experiment 1 , no difference $(P=0.51)$ existed in the response to the ovalbumin challenge, as anti-ovalbumin IgG production was similar between treatment groups (Figure $3 \mathrm{~A}$ ). In experiment 2, again no treatment effect existed in the production of IgG against ovalbumin $(P=0.92$; Figure $3 \mathrm{~B})$. However, a treatment by time interaction $(P<0.001)$ was detected, such that the calves that received pooled colostrum from CL cows tended to have a greater response at $\mathrm{d} 18(P=$ $0.07)$ and had a greater response at d $28(P<0.001)$, before the second injection, compared with calves that received colostrum from HT cows. In contrast, calves that received colostrum from HT cows had a greater response at $\mathrm{d} 42(P=0.01), 49(P=0.02)$, and $56(P$ $=0.03)$ compared with calves that received colostrum from CL cows.

\section{Serum Cortisol}

Overall serum cortisol concentration during the preweaning period was greater $(P=0.02)$ for calves born to CL cows compared with those born to HT cows $(1.62$ \pm 0.11 vs. $1.25 \pm 0.12 \mu \mathrm{g} / \mathrm{dL}$; Figure 4$)$. Serum cortisol concentration tended to have a treatment by time interaction $(P=0.09)$, such that CL calves had greater serum cortisol concentration at d $4(P=0.03)$. 


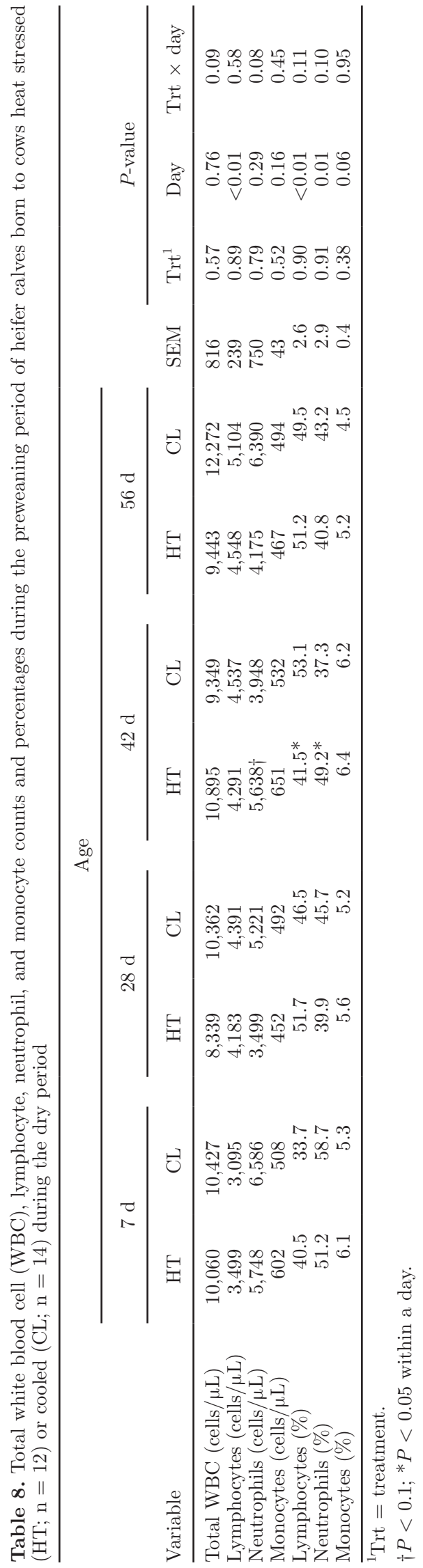

\section{Whole-Blood Cell Proliferation}

In experiment 1 , no effect of treatment $(P=0.99)$ was detected on whole-blood cell proliferation, but a treatment by time interaction $(P=0.001)$ was detected, such that HT calves had a greater response at d $7(P=$ $0.03)$ compared with CL calves $(124.8 \pm 50.1$ vs. $45.1 \pm$ 44.4 net cpm/100 cells, respectively) and CL calves had a greater $(P=0.003)$ response at d 42 compared with HT calves $(282.9 \pm 34.9$ vs. $105.0 \pm 44.0$ net $\mathrm{cpm} / 100$ cells, respectively; Figure 5).

In experiment 2 , no difference $(P=0.49)$ was observed for whole-blood cell proliferation between calves that received colostrum from HT cows compared with those that received colostrum from CL cows (Figure 6).

\section{DISCUSSION}

The effectiveness of the evaporative cooling system used in experiment 1 for the dry cows was verified by the lower rectal temperature and respiration rate of CL cows when compared with those without the cooling system, despite being exposed to a similar temperaturehumidity index. As described in other studies, relative to CL cows, HT cows had lower DMI and BW gain during the dry period (Tao et al., 2011), shorter dry period and gestation length (do Amaral et al., 2009, 2011; Tao et al., 2011), lower calf weight at birth (Adin et al., 2009; do Amaral et al., 2011), greater prolactin concentrations in plasma (do Amaral et al., 2010, 2011), and lower milk production in the next lactation (do Amaral et al., 2009; Tao et al., 2011). All these observations provide evidence about the success of the HT model in the present experiment; thus, it was appropriate to investigate the effects of HT or CL during the dry period on factors related to calf and colostrum.

As demonstrated in other studies with dairy cows (Collier et al., 1982; Tao et al., 2012a) and sheep (Brown et al., 1977), newborns from HT dams were lighter at birth compared with those from CL dams. The compromised fetal growth in calves from HT dams can be explained by several factors, such as the shorter gestation length and impaired placental function during late gestation. As discussed by Tao et al. (2012a), the shorter gestation length does not explain all the differences observed in birth weights between treatments. In the present study, the gestation length was $3.8 \mathrm{~d}$ shorter in HT dams and their calves were $4.8 \mathrm{~kg}$ lighter at birth compared with CL dams. Considering that a fetus of a Holstein dairy cow gains about 0.5 $\mathrm{kg} / \mathrm{d}$ during the last week of gestation (Muller et al., 1975), in the current study, the shorter gestation length observed in HT cows accounts for about $40 \%$ of the lower birth weight of their calves. The reason for the additional reduction in $\mathrm{BW}$ is likely to be related to the 
Table 9. Health scores and white blood cell (WBC) count during the preweaning period of calves born to cows under thermoneutral conditions during the dry period and fed frozen colostrum from cows exposed to either heat stress (HT colostrum; $\mathrm{n}=17)$ or cooling $(\mathrm{CL}$ colostrum; $\mathrm{n}=$ 16) during the dry period

\begin{tabular}{|c|c|c|c|c|c|c|}
\hline Variable & \multicolumn{2}{|c|}{ Treatment } & SEM & \multicolumn{3}{|c|}{$P$-value } \\
\hline Fecal score $(0-3)$ & 1.29 & 1.39 & 0.06 & 0.22 & $<0.01$ & 0.92 \\
\hline Respiratory score $(0-12)$ & 2.55 & 2.36 & 0.09 & 0.15 & $<0.01$ & 0.95 \\
\hline Rectal temperature $\left({ }^{\circ} \mathrm{C}\right)$ & 38.90 & 38.80 & 0.03 & $<0.01$ & $<0.01$ & 0.85 \\
\hline Lymphocytes (cells $/ \mu \mathrm{L})$ & 4,323 & 4,555 & 266 & 0.54 & 0.06 & 0.78 \\
\hline Neutrophils (cells $/ \mu \mathrm{L}$ ) & 3,935 & 3,687 & 451 & 0.70 & $<0.01$ & 0.78 \\
\hline Monocytes (cells $/ \mu \mathrm{L})$ & 715 & 762 & 101 & 0.74 & 0.03 & 0.89 \\
\hline Lymphocytes (\%) & 49.2 & 51.5 & 2.7 & 0.55 & $<0.01$ & 0.88 \\
\hline Neutrophils (\%) & 40.3 & 36.9 & 2.6 & 0.37 & $<0.01$ & 0.96 \\
\hline Monocytes (\%) & 7.8 & 8.1 & 0.7 & 0.75 & 0.08 & 0.52 \\
\hline
\end{tabular}

${ }^{1}$ White blood cell count was performed for a subset of animals (HT $=9 ; \mathrm{CL}=8$ ) and blood samples were taken at d 14, 28, 42, and 56 of age.

overall effect of HT during the whole dry period, such as impairment of placental function, rather than only during the last week of gestation.

Inadequate maternal nutrition is one of the major factors that impair fetal growth (Wu et al., 2006). A study with Hereford cows showed that submaintenance levels of nutrition during the last trimester reduced calf birth weight (Tudor, 1972). However, the animals in that experiment were severely energy restricted and cannot be compared with the animals in the present study and other studies (Adin et al., 2009; do Amaral et al., 2009; Tao et al., 2011) in which the decrease in DMI in heat-stressed cows was only about 10 to $15 \%$ relative to CL cows. Indeed, another study with beef cattle restricted intake for both protein and energy by $43 \%$ of NRC requirements during the last $90 \mathrm{~d}$ of gestation and did not report any effect on gestation length of cows or birth weight of calves (Hough et al., 1990).

The nutrient uptake by the fetus can be determined by both blood flow rate and nutrient concentration in the arterial and venous supply to the uterus (Reynolds et al., 2006). Heat stress during gestation decreases uteroplacental blood flow (Reynolds et al., 2005) and reduces placental transport of oxygen and nutrient transfer from the dam to the fetus (Wallace et al., 2002), which result in reduced placental and fetal growth. Additionally, Thompson et al. (2013) observed that cows heat stressed during the dry period had lower plasma pregnancy-specific protein $\mathrm{B}$ concentration during the last week of pregnancy compared with CL cows, which also reflects altered placental development. Thus, thermal stress per se leads to intrauterine growth restriction in animals (Reynolds et al., 1985, 2005; Wallace et al., 2005), which may account for part of the decrease in birth weight of HT calves relative to CL calves.
Consistent with results obtained in a previous study (Tao et al., 2012a), the lower BW and WH in HT calves relative to CL calves during the first $2 \mathrm{mo}$ of life can be interpreted as a consequence of the lower birth weight, because no differences in weight gain or height increase were observed at $60 \mathrm{~d}$ of age. By design, there was a lack of difference in birth weight between treatments in experiment 2 , so any treatment effect was not influenced by differences in birth weight. Because treatments did not have an effect on BW and $\mathrm{WH}$ up to d 60, we conclude that colostrum from dry-period HT cows did not impair preweaning growth of calves compared with colostrum from CL cows.

In contrast to other studies (Nardone et al., 1997; Adin et al., 2009), in the present study, HT during the dry period had no effect on colostrum IgG concentration. However, the results of the present study are in accordance with findings in a previous study (Tao et al., 2012a) using the same experimental model. Additionally, as opposed to Tao et al. (2012a), in experiment 1 , no differences in hematocrit, or total plasma protein or total serum IgG concentrations was observed during the first month of age. In Tao et al. (2012a), dairy calves heat stressed in utero during the dry period had lower hematocrit levels at birth before colostrum feeding and lower total plasma protein and total serum IgG concentrations after $1 \mathrm{~d}$ of age and during the following $27 \mathrm{~d}$ compared with calves cooled in utero. However, in that study, calves received fresh colostrum from their own dams, instead of frozen and thawed pooled colostrum as in the current experiment, which may explain the differences in total plasma protein and total $\operatorname{IgG}$ concentrations after colostrum feeding. Despite the fact that freezing colostrum does not affect IgG availability and absorption by the calf (Stieler et al., 2012), live 


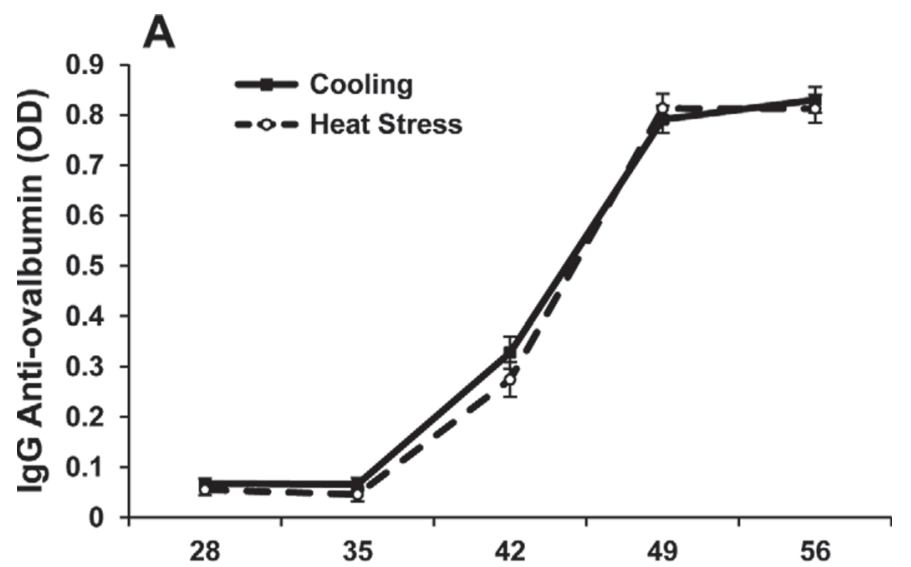

B

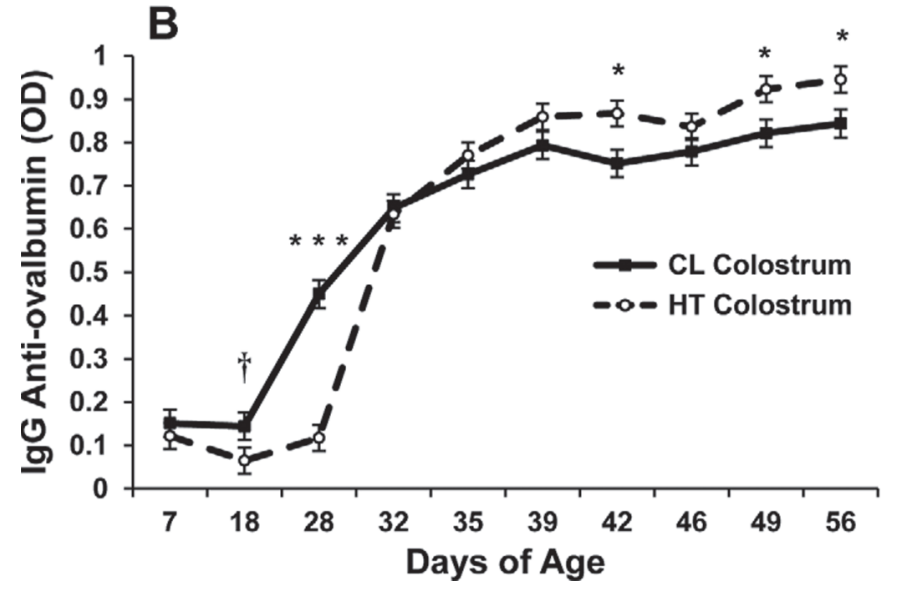

Figure 3. Effect of treatment on the response of calves to ovalbumin challenge. (A) Calves were born to heat-stressed (HT) or cooled (CL) cows during the dry period and fed pooled colostrum from cows exposed to thermoneutral conditions during the dry period. (B) Calves born to cows exposed to thermoneutral conditions during the dry period were fed colostrum from heat-stressed (HT colostrum) or cooled (CL colostrum) cows during the dry period. One milliliter of ovalbumin solution containing albumin from chicken egg white $(0.5$ $\mathrm{mg} / \mathrm{mL}$ ) was injected s.c. at d 28 and 42 of age (A) or at d 7, 28, anc 42 of age (B). Results are expressed as optical density (OD). Error bars represent SEM. Calves from HT cows had similar $(P=0.51)$ anti-ovalbumin IgG overall production relative to CL calves. No effect of colostrum $(P=0.92)$ was observed on the overall production of $\operatorname{IgG}$ against ovalbumin. However, a treatment by time interaction $(P<$ $0.001)$ was observed. ${ }^{* * *} P<0.001 ;{ }^{*} P<0.05 ; \dagger P<0.10$.

cells present in fresh colostrum are destroyed during the freezing process (Holloway et al., 2001).

Evidence exists to support the concept that maternal leukocytes in colostrum cross the neonatal gut and circulate in the newborn calf, but the effect of these cells on the development of neonatal immunity has not yet been determined (Reber et al., 2006; Donovan et al., 2007). Reber et al. $(2005,2008)$ demonstrated that feeding maternal colostrum containing leukocytes to the neonatal calf enhances development of lymphocytes and antigen-presenting function; therefore, it also enhances activation of lymphocytes and development of

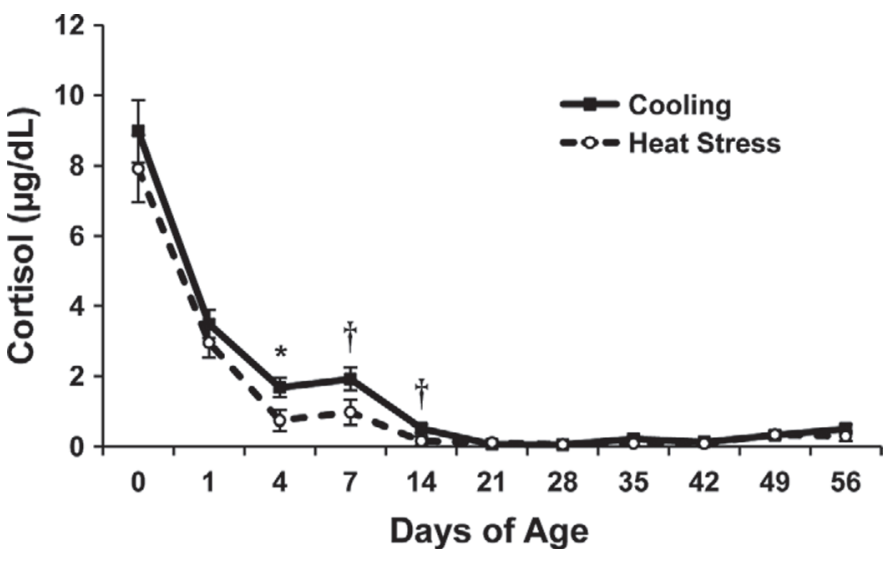

Figure 4. Effect of heat stress or cooling during the dry period on the serum cortisol concentration of the offspring during the preweaning period. Error bars represent SEM. Heat stress during the dry period decreased $(P=0.02)$ overall serum cortisol concentration of calves compared with cooling. ${ }^{*} P<0.05 ; \dagger P<0.10$.

the acquired immune response. Because live whole cells are not present in frozen colostrum, the calves in the present study may not have the contribution from colostral cells to enhance overall protein concentration in plasma, such as immunoglobulins produced by B cells. Most of the cells present in colostrum are leukocytes and range in concentration between $1 \times 10^{6}$ and $3 \times$ $10^{6}$ cells $/ \mathrm{mL}$ (Lee et al., 1980). The majority of these leukocytes are macrophages (40 to 50\%) and a smaller fraction consists of lymphocytes (22 to $25 \%$ ) and neutrophils (25 to 37\%; Liebler-Tenorio et al., 2002; Reber et al., 2005). Yet, most of the lymphocytes are T lymphocytes rather than $\mathrm{B}$ lymphocytes, which make up only $5 \%$ of the total cells or between $41.8 \times 10^{6}$ and $142.5 \times 10^{6} \mathrm{~B}$ cells in $3.8 \mathrm{~L}$ of colostrum. The propor-

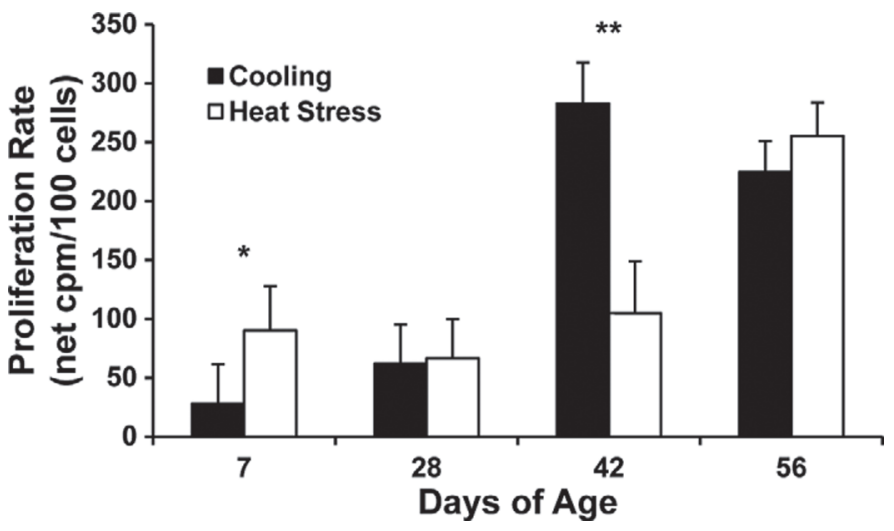

Figure 5. Effect of heat stress (HT) or cooling (CL) during the dry period on the whole-blood (WB) cell proliferation of the offspring during the preweaning period. Error bars represent SEM. An effect of treatment was not observed $(P=0.99)$ for the overall WB cell proliferation, but a treatment by time interaction $(P=0.001)$ was observed. ${ }^{* *} P<0.01 ;{ }^{*} P<0.05$. 


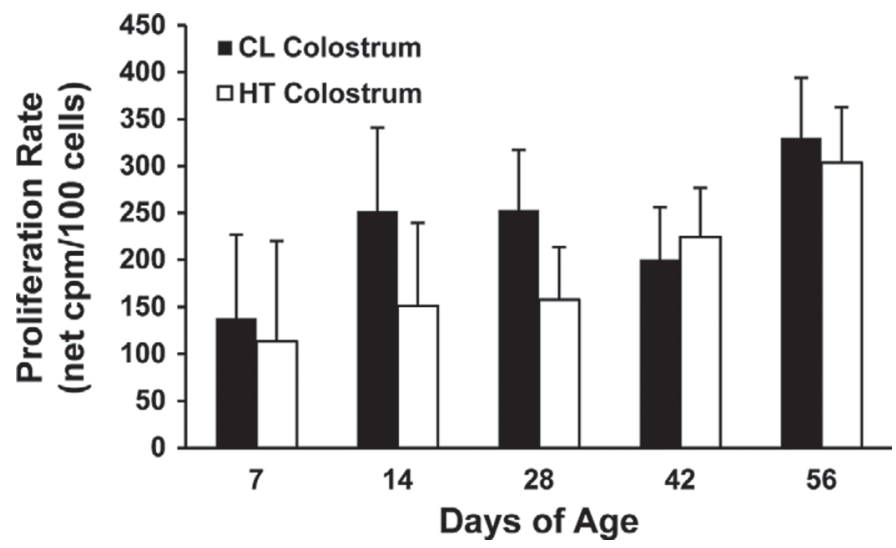

Figure 6. Effect of feeding colostrum from heat-stressed (HT) or cooled (CL) cows during the dry period on the whole-blood cell proliferation of the offspring during the preweaning period. Calves were born to cows exposed to thermoneutral conditions during the dry period. Error bars represent SEM. No difference $(P=0.49)$ between treatments was observed.

tion of B cells absorbed by the calf and the amount of protein that those $\mathrm{B}$ cells would be able to produce in $24 \mathrm{~h}$ are hard to estimate but cannot be excluded.

Clearly, the difference in hematocrit at birth observed in Tao et al. (2012a) is not related to the type of colostrum fed. Those authors hypothesized that the lower hematocrit in HT calves was a postnatal adaptation to the intrauterine hypoxia. In experiment 2 , no differences in hematocrit or total plasma protein concentration was observed during the first month of age, suggesting that frozen and thawed colostrum from HT cows per se does not seem to affect those hematological parameters. Therefore, the lower total plasma protein and hematocrit found in Tao et al. (2012a) during the first month of age of HT calves could be a result of a complementary effect between feeding fresh colostrum from HT cows and calves heat stressed in utero.

Data related to the effects of prepartum HT on passive immune transfer of neonates are limited. A study conducted in sows (Machado-Neto et al., 1987) observed a lower IgG concentration in the serum of piglets from sows heat stressed during late gestation, but the concentration of $\mathrm{IgG}$ in the colostrum also tended to be lower in heat-stressed sows. In the present study, passive immune transfer was compromised in calves born to HT cows, as verified by lower AEA compared with those born to CL cows. The same effect was observed by Tao et al. (2012a); however, in the current study, HT and CL calves received the same colostrum, eliminating a possible influence of source of colostrum on the efficiency of $\operatorname{IgG}$ absorption. However, we are not able to conclude from the current experiment if the lower IgG absorption of HT calves was due to a decrease in the ability of the small intestine to absorb IgG or to the smaller intestinal contact surface area, as a consequence of the lower birth weight of those calves, or a combination of both. Thus, the mechanisms of impaired IgG absorption by HT in utero are still not clear. In experiment 2, total serum IgG concentration tended to differ between treatments, which can be explained by the difference in mass of IgG between the pooled colostrum fed in each treatment (i.e., 3.8 L of colostrum from CL cows provided about $50 \mathrm{~g}$ less IgG to the calves than did colostrum from HT cows). However, when AEA was analyzed, no difference between treatments was detected. Thus, frozen and thawed colostrum from dryperiod HT or CL cows had no influence on intestinal IgG uptake in neonatal calves.

Calves from CL dams had greater overall serum cortisol concentration, different from what was observed in Tao et al. (2012a), wherein differences were observed only at birth. In that study, differences were attributed to greater sensitivity to the stress of birth experienced by CL calves. In the current study, the greater cortisol levels detected in CL calves during the first 2 wk of age is intriguing, as the animals were managed identically after birth. This result may suggest greater sensitivity of CL calves to the stress resulted from the routine management during the first $2 \mathrm{wk}$ of age.

Heat stress in utero during late gestation seems to affect cellular immunity of calves during the preweaning period, as CL calves had a greater response at d 42 in the whole-blood cell proliferation assay compared with HT calves. On the other hand, HT calves had a greater response at d 7. Glucocorticoids, such as cortisol, are known as immunosuppressive agents (Baschant and Tuckermann, 2010). Therefore, the lower proliferative responses of CL calves at d 7 may partly result from the greater circulating cortisol from 4 to $14 \mathrm{~d}$ of age. Additionally, our preliminary study (study performed with the slaughtered bull calves from experiment 1) also indicates that the thymus of bull calves born to cows heat stressed during late gestation tend to be proportionally bigger at $\mathrm{d} 7$ of age $(0.14 \pm 0.03$ vs. 0.9 $\pm 0.03 \%$ of $\mathrm{BW} ; P=0.08)$ relative to those born to CL cows (our unpublished data). Thymus gland is a primary lymphoid organ in which bone marrow-derived T-lymphocyte precursors undergo maturation (Anderson et al., 1996). Thus, these preliminary data may suggest a greater capacity of T-lymphocyte development and proliferation at that age in HT calves, which may also explain the greater whole-blood cell proliferation compared with CL calves. The increased response at d 42 in both treatments may be related to the timing of the ovalbumin challenge, which started at d 28 , so by d 42 more activated lymphocytes were present in the peripheral circulation of the calves. Additionally, the greater response by CL calves at d 42 suggests an 
enhanced immune system development, especially thymus development, in CL calves or a delay in that from HT calves. David et al. (2003) found lower lymphocyte proliferative rates in lymphoid tissues, including the thymus, from preterm calves born to cows whose parturition was induced $12 \mathrm{~d}$ before the expected calving date. Therefore, a delay in the immune system development of HT calves could be explained by the shorter gestation length experienced by their dams. Moreover, the similar response at $\mathrm{d} 56$ indicates that both groups have an equally well-developed immune system by that age. In experiment 2, the lack of difference between treatments for whole-blood cell proliferation suggests that the sources of colostrum do not seem to affect cellular immunity of calves during the preweaning period.

The ovalbumin challenge performed in experiment 1 led to the production of similar amounts of IgG antiovalbumin by both treatment groups, suggesting that HT in utero does not impair the humoral immune response in calves from $28 \mathrm{~d}$ of age to weaning, as previously reported by Tao et al. (2012a). Interestingly, in experiment 2, calves that received colostrum from CL cows responded to the first injection of ovalbumin at d 7, whereas those that received colostrum from HT cows only responded after the second injection at $\mathrm{d}$ 28. Thus, the B-cell response of calves that received HT colostrum was delayed compared with those that received CL colostrum, which may reflect a delay in the development of lymphoid organs in calves fed HT colostrum. Colostrum contains important immunologic components besides immunoglobulins and maternal leukocytes, such as cytokines and growth and metabolic factors (Sangild, 2003), but their roles are not yet well understood. A study with human colostrum demonstrated that bioactive immunologic factors, such as growth factor and cytokines, were not affected by freezing storage $\left(-20^{\circ} \mathrm{C}\right)$ up to 6 mo (Ramírez-Santana et al., 2012); therefore, these factors were probably not affected in the colostrum used in the present study. A study with pigs demonstrated that colostral cytokines are absorbed and also can be detected in the blood of the piglet (Nguyen et al., 2007). Moreover, Julius et al. (1988) found that a bioactive peptide isolated from sheep colostrum enhances proliferation of resting B cells from mice neonates. Thus, another colostral component, such as cytokines, transfer factors, and products of cellular destruction of leukocytes during the freezing process, may affect the development of lymphoid organs for B-lymphocytes during neonatal development, such as the ileal Peyer's patches (Parng et al., 1996), which may explain the different B-cell responses to ovalbumin challenge between calves that received HT and CL colostrum.

\section{CONCLUSIONS}

Maternal HT during late gestation decreased calf birth weight and weaning weight and compromised the passive IgG transfer, regardless of colostrum source. Feeding colostrum from HT cows during the dry period did not affect AEA or growth performance during the preweaning period, but seemed to impair humoral immune response during the first month of life. Further studies are necessary to further understand the effects of HT in utero on mechanisms of hyperthermia-induced intrauterine growth retardation, compromised AEA of IgG and cellular immunity, and the effects of feeding colostrum from HT cows on the calf's overall immune response.

\section{ACKNOWLEDGMENTS}

The authors thank the staff of the Dairy Unit of University of Florida (Gainesville) for animal care and data collection. Support was provided by the USDA Agriculture and Food Research Initiative (AFRI) Integrated Solutions for Animal Agriculture (Washington, DC; Award \#2010-85122-20623 to G. E. Dahl) and the National Science Foundation (Arlington, VA; Award \#1247362 to G. E. Dahl).

\section{REFERENCES}

Adin, G., A. Gelman, R. Solomon, I. Flamenbaum, M. Nikbachat, E. Yosef, A. Zenou, A. Shamay, Y. Feuermann, S. J. Mabjeesh, and J. Miron. 2009. Effects of cooling dry cows under heat load conditions on mammary gland enzymatic activity, intake of food water, and performance during the dry period and after parturition. Livest. Sci. 124:189-195.

Alexander, G., and D. Williams. 1971. Heat stress and development of the conceptus in domestic sheep. J. Agric. Sci. 76:53-72.

Anderson, G., N. C. Moore, J. J. Owen, and E. J. Jenkinson. 1996. Cellular interactions in thymocyte development. Annu. Rev. Immunol. 14:73-99.

Baschant, U., and J. Tuckermann. 2010. The role of the glucocorticoid receptor in inflammation and immunity. J. Steroid Biochem. Mol. Biol. 120:69-75.

Brown, D. E., P. C. Harrison, F. C. Hinds, J. A. Lewis, and M. H. Wallace. 1977. Heat stress effects on fetal development during late gestation in the ewe. J. Anim. Sci. 44:442-446.

Collier, R. J., S. G. Doelger, H. H. Head, W. W. Thatcher, and C. J. Wilcox. 1982. Effects of heat stress during pregnancy on maternal hormone concentrations, calf birth weight and postpartum milk yield of Holstein cows. J. Anim. Sci. 54:309-319.

David, C. W., J. Norrman, H. M. Hammon, W. C. Davis, and J. W. Blum. 2003. Cell proliferation, apoptosis, and B- and T-lymphocytes in Peyer's patches of the ileum, in thymus and in lymph nodes of preterm calves, and in full-term calves at birth and on day 5 of life. J. Dairy Sci. 86:3321-3329.

do Amaral, B. C., E. E. Connor, S. Tao, M. J. Hayen, J. W. Bubolz, and G. E. Dahl. 2009. Heat-stress abatement during the dry period: Does cooling improve transition into lactation? J. Dairy Sci. 92:5988-5999.

do Amaral, B. C., E. E. Connor, S. Tao, M. J. Hayen, J. W. Bubolz, and G. E. Dahl. 2010. Heat stress abatement during the dry pe- 
riod influences prolactin signaling in lymphocytes. Domest. Anim. Endocrinol. 38:38-45.

do Amaral, B. C., E. E. Connor, S. Tao, M. J. Hayen, J. W. Bubolz, and G. E. Dahl. 2011. Heat stress abatement during the dry period influences metabolic gene expression and improves immune status in the transition period of dairy cows. J. Dairy Sci. 94:86-96.

Donovan, D. C., A. J. Reber, J. D. Gabbard, M. Aceves-Avila, K. L. Galland, K. A. Holbert, L. O. Ely, and D. J. Hurley. 2007. Effect of maternal cells transferred with colostrum on cellular responses to pathogen antigens in neonatal calves. Am. J. Vet. Res. 68:778-782.

Donovan, G. A., L. Badinga, R. J. Collier, C. J. Wilcox, and R. K. Braun. 1986. Factors influencing passive transfer in dairy calves. J. Dairy Sci. 69:754-759.

Holloway, N. M., J. W. Tyler, J. Lakritz, S. L. Carlson, and J. Holle. 2001. Serum immunoglobulin G concentrations in calves fed fresh and frozen colostrum. J. Am. Vet. Med. Assoc. 219:357-359.

Hough, R. L., F. D. McCarthy, H. D. Kent, D. E. Eversole, and M. L. Wahlberg. 1990. Influence of nutritional restriction during late gestation on production measures and passive immunity in beef cattle. J. Anim. Sci. 68:2622-2627.

Julius, M. H., M. Janusz, and J. Lisowski. 1988. A colostral protein that induces the growth and differentiation of resting B lymphocytes. J. Immunol. 140:1366-1371.

Lee, C. S., F. B. Wooding, and P. Kemp. 1980. Identification, properties, and differential counts of cell populations using electron microscopy of dry cows secretions, colostrum and milk from normal cows. J. Dairy Res. 47:39-50.

Liebler-Tenorio, E. M., G. Riedel-Caspari, and J. F. Pohlenz. 2002. Uptake of colostral leukocytes in the intestinal tract of newborn calves. Vet. Immunol. Immunopathol. 85:33-40.

Machado-Neto, R., C. N. Graves, and S. E. Curtis. 1987. Immunoglobulins in piglets from sows heat-stressed prepartum. J. Anim. Sci. 65:445-455.

Mallard, B. A., L. C. Wagter, M. J. Ireland, and J. C. Dekkers. 1997. Effects of growth hormone, insulin-like growth factor-I, and cortisol on periparturient antibody response profiles of dairy cows. Vet. Immunol. Immunopathol. 60:61-76.

Muller, L. D., G. L. Beardsley, R. P. Ellis, D. E. Reed, and M. J. Owens. 1975. Calf response to the initiation of parturition in dairy cows with dexamethasone or dexamethasone with estradiol benzoate. J. Anim. Sci. 41:1711-1716.

Nardone, A., N. Lacetera, U. Bernabucci, and B. Ronchi. 1997. Composition of colostrum from dairy heifers exposed to high air temperatures during late pregnancy and the early postpartum period. J. Dairy Sci. 80:838-844.

Nguyen, T. V., L. Yuan, M. S. P. Azevedo, K.-I. Jeong, A.-M. Gonzalez, and L. J. Saif. 2007. Transfer of maternal cytokines to suckling piglets: In vivo and in vitro models with implications for immunomodulation of neonatal immunity. Vet. Immunol. Immunopathol. 117:236-248.

Oakes, G. K., A. M. Walker, R. A. Ehrenkranz, R. C. Cefalo, and R. A. Chez. 1976. Uteroplacental blood flow during hyperthermia with and without respiratory alkalosis. J. Appl. Physiol. 41:197-201.

Parng, C.-L., S. Hansal, R. A. Goldsby, and B. A. Osborne. 1996. Gene conversion contributes to Ig light chain diversity in cattle. J. Immunol. 157:5478-5486.

Quigley, J. D., III, and J. J. Drewry. 1998. Nutrient and immunity transfer from cow to calf pre- and postcalving. J. Dairy Sci. 81:2779-2790.

Quigley, J. D., III, D. L. Fike, M. N. Egerton, J. J. Drewry, and J. D. Arthington. 1998. Effects of a colostrum replacement product derived from serum on immunoglobulin $\mathrm{G}$ absorption by calves. J. Dairy Sci. 81:1936-1939.

Ramírez-Santana, C., F. J. Pérez-Cano, C. Audí, M. Castell, M. G. Moretones, M. C. López-Sabater, C. Castellote, and A. Franch. 2012. Effects of cooling and freezing storage on the stability of bioactive factors in human colostrum. J. Dairy Sci. 95:2319-2325.

Reber, A. J., D. C. Donovan, J. Gabbard, K. Galland, M. AcevesAvila, K. A. Holbert, L. Marshall, and D. J. Hurley. 2008. Transfer of maternal colostral leukocytes promotes development of the neonatal immune system: Part II. Effects on neonatal lymphocytes. Vet. Immunol. Immunopathol. 123:305-313.

Reber, A. J., A. R. Hippen, and D. J. Hurley. 2005. Effects of the ingestion of whole colostrum or cell-free colostrum on the capacity of leukocytes in newborn calves to stimulate or respond in one-way mixed leukocyte cultures. Am. J. Vet. Res. 66:1854-1860.

Reber, A. J., A. Lockwood, A. R. Hippen, and D. J. Hurley. 2006. Colostrum induced phenotypic and trafficking changes in maternal mononuclear cells in peripheral blood leukocyte model for study of leukocyte transfer to the neonatal calf. Vet. Immunol. Immunopathol. 109:139-150.

Reynolds, L. P., P. P. Borowicz, K. A. Vonnahme, M. L. Johnson, A. T. Grazul-Bilska, D. A. Redmer, and J. S. Caton. 2005. Placental angiogenesis in sheep models of compromised pregnancy. J. Physiol. 565:43-58.

Reynolds, L. P., J. S. Caton, D. A. Redmer, A. T. Grazul-Bilska, K. A. Vonnahme, P. P. Borowicz, J. S. Luther, J. M. Wallace, G. Wu, and T. E. Spencer. 2006. Evidence for altered placental blood flow and vascularity in compromised pregnancies. J. Physiol. 572:51-58.

Reynolds, L. P., C. L. Ferrell, J. A. Nienaber, and S. P. Ford. 1985. Effects of chronic environmental heat stress on blood flow and nutrient uptake of the gravid bovine uterus and fetus. J. Agric. Sci. 104:289-297.

Sangild, P. T. 2003. Uptake of colostral immunoglobulins by the compromised newborn farm animals. Acta Vet. Scand. Suppl. $98: 105-122$.

School of Veterinary Medicine, University of Wisconsin-Madison. 2011. Calf health scoring chart and calf health scoring criteria. Calves. Accessed July 15, 2011. http://www.vetmed.wisc.edu/dms/fapm/ fapmtools/8calf/calf_health_scoring_chart.pdf.

Stieler, A., B. S. Bernardo, and G. A. Donovan. 2012. Neutrophil and monocyte function in neonatal dairy calves fed fresh or frozen colostrum. Int. J. Appl. Res. Vet. Med. 10:328-334.

Stott, G. H., F. Wiersma, B. E. Menefee, and F. R. Radwanski. 1976 Influence of environment on passive immunity in calves. J. Dairy Sci. 59:1306-1311.

Tao, S., J. W. Bubolz, B. C. do Amaral, I. M. Thompson, M. J. Hayen, S. E. Johnson, and G. E. Dahl. 2011. Effect of heat stress during the dry period on mammary gland development. J. Dairy Sci. 94:5976-5986.

Tao, S., A. P. Monteiro, I. M. Thompson, M. J. Hayen, and G. E. Dahl 2012a. Effect of late-gestation maternal heat stress on growth and immune function of dairy calves. J. Dairy Sci. 95:7128-7136.

Tao, S., I. M. Thompson, A. P. A. Monteiro, M. J. Hayen, L. J. Young, and G. E. Dahl. 2012b. Effect of cooling heat-stressed dairy cows during the dry period on insulin response. J. Dairy Sci. 95:50355046 .

Thompson, I. M., and G. E. Dahl. 2012. Dry period seasonal effects on the subsequent lactation. Prof. Anim. Sci. 28:628-631.

Thompson, I. M., S. Tao, J. Branen, A. D. Ealy, and G. E. Dahl 2013. Environmental regulation of pregnancy-specific protein B concentrations during late pregnancy in dairy cattle. J. Anim. Sci. 91:168-173.

Tudor, G. D. 1972. The effect of pre- and post-natal nutrition on the growth of beef cattle I. The effect of nutrition and parity of the dam on calf birth weight. Aust. J. Agric. Res. 23:389-395.

Wallace, J. M., D. A. Bourke, R. P. Aitken, N. Leitch, and W. W. Hay Jr. 2002. Blood flows and nutrient uptakes in growth-restricted pregnancies induced by overnourishing adolescent sheep. Am. J. Physiol. Regul. Integr. Comp. Physiol. 282:R1027-R1036.

Wallace, J. M., T. R. Regnault, S. W. Limesand, W. W. Hay Jr., and R. V. Anthony. 2005. Investigating the causes of low birth weight in contrasting ovine paradigms. J. Physiol. 565:19-26.

Wu, G., F. W. Bazer, J. M. Wallace, and T. E. Spencer. 2006. BoardInvited Review: Intrauterine growth retardation: Implications for the animal sciences. J. Anim. Sci. 84:2316-2337. 